Editorial

\title{
The Movement System and Physical Therapist Practice: What Does the Future Look Like?
}

\author{
Barbara J Hoogenboom, PT EdD, SCS, AT-Ret ${ }^{1}$ a \\ 1 Grand Valley State University, Grand Rapids, MI, USA \\ Keywords: movement system, physical therapy, sports medicine, sports pt \\ https://doi.org/10.26603/001c.30999
}

\section{International Journal of Sports Physical Therapy}

Vol. 17, Issue 1, 2022

When I think of the human movement system, the words poetry in motion come to mind: the mixture of fluidity and coordination of motion, enhanced by power, speed, and precision. What an awesome and amazing combination!

The definition of poetry in motion:

"Someone or something that moves in a way that is very graceful or beautiful." 1

Sports provides a multitude of examples of beauty, intensity, control, and precision during movement:

The combination of power and grace during gymnastics (Figure 1) and figure skating performances...

The propulsion of the body through space in diving, pole vault (Figure 2), long jump or high jump...

The reception of a perfectly thrown spiral; fielding a seemingly impossible infield shot, and turning it into a double play...

The end of a race "kick" by a runner (Figure 3 )...

Grace and controlled power demonstrated in many forms of the martial arts....

Examples abound. Each reader will summon mental images of what "poetry in motion" means to them and which athletes exemplify this standard of movement. Honestly, I have seldom thought about sport in terms of words or poetry, but who hasn't thought of many parts of sport as art? As sports physical therapists we see poetry in motion or artistry every day, in the movements of our athletes. When the synchrony of body movements is altered, we seek to restore it along a continuum from basic (or fundamental) to extremely high levels of movement.

The movement system has been centrally described and suggested by the American Physical Therapy Association (APTA) as the foundation for the practice of physical therapy. I was an invited participant in the Movement System Summit in 2016 where around 100 physical therapists gathered to discuss many aspects of the movement system. (Figure 4) This opportunity provided me with an ongoing sense of investment in and curiosity about the movement system and how it could affect physical therapist practice including education, research, and clinical practice.

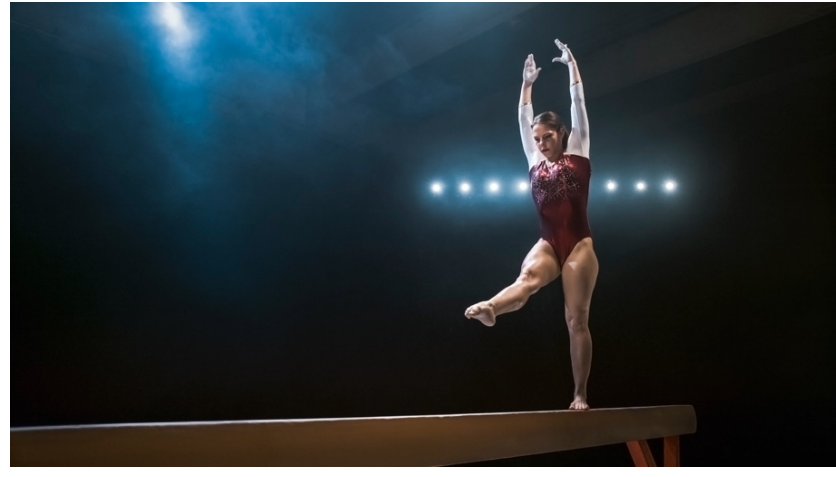

Figure 1. A Gymnast on the balance beam, an example of strength, power, and grace combined

iStock photo

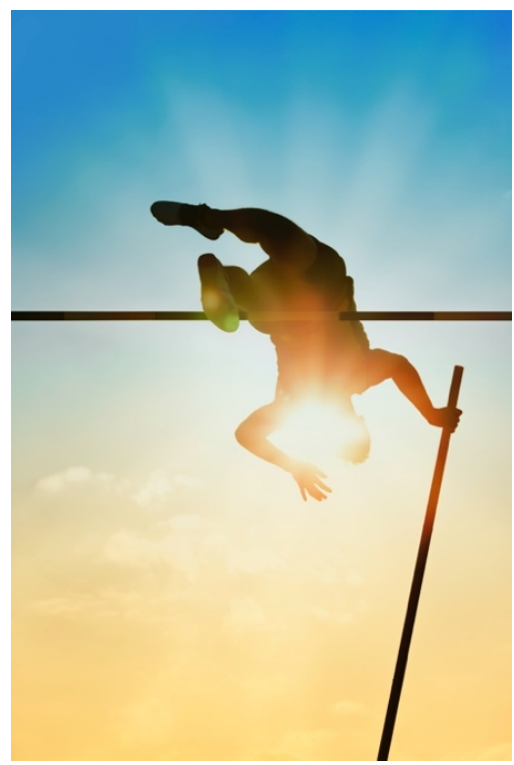

Figure 2. A pole vaulter, demonstrating propulsion, and proprioceptive acuity while in flight

iStock photo 
In 2019 the official definition of the human movement system was revised to:

\section{"The integration of body systems that generate and maintain movement at all levels of bodily function" 2}

I believe that many practicing sports physical therapists have been movement system practitioners for our entire careers, linking functional performance (or lack thereof!) to deficits in the various systems comprising the human movement system. I see the transition to movement system language and thinking as a natural transition for the sports physical therapist from "function" or "functional movement" to a systems-based approach that intentionally encompasses all aspects of the human movement system. Authors of papers in this special issue have endeavored to articulate the links between systems and how these links may impact many aspects of physical therapist practice. It is not a big leap. I have always said that the best sports physical therapists are not only experts in musculoskeletal care, but have in-depth working expertise in the equally important contributory systems: endocrine, neuromuscular, integumentary, and cardiovascular and pulmonary. Without each of the systems, where would our athletes be?

Movement is what we are about, movement analysis it is what we do, in the context of primary prevention, examination, intervention(s), and return to sport decisions. Movement analysis may be visual, use video, or even 3D motion capture, but we commonly tie progress (or lack thereof), changes in intervention(s), and decisions regarding return to play to analysis of the entire movement system. As physical therapists, we are the profession best suited to examine, analyze, and address deficits in movement using all of our senses. ${ }^{3}$ Visual task analysis (clinical observation), ${ }^{4}$ feeling movement (tactile analysis), ${ }^{3}$ and auditory assessment ${ }^{3}$ are linked to contribute to the appraisal of the overall function of the movement system. The APTA's proposed movement system screening tool developed in 2018 is intended for use by physical therapists in all areas of practice. This screening tool encompasses performance of several common movement-based tasks and serves to assist the therapist in identifying additional tests and measures to be used during examination and denote symptom provocation, is available as an appendix to Dr. Sahrmann's paper.

In Sebleski et al. ${ }^{3}$ I suggested a nomenclature change from "home exercise program (HEP)" to "movement optimization program (MOP)" and that this change in words could better encapsulate the array of interventions that are chosen by a physical therapist that are focused on enhancing movement. A MOP may be more than just "exercise," and may include many other strategies to enhance movement. Will this label for what we do with patients change? Perhaps other parts of our language will transform as collective understanding of the movement system changes, and we will need to adapt...who knows?

Where are we headed? For many of us it will feel much like it is business as usual. But for those who have not considered all systems contributing to every aspect of human movement, it may be a paradigm shift. The ongoing prioritization and contributions of the APTA in the promotion and adoption of the movement system as a central organizing principle for the profession are currently undefined. I

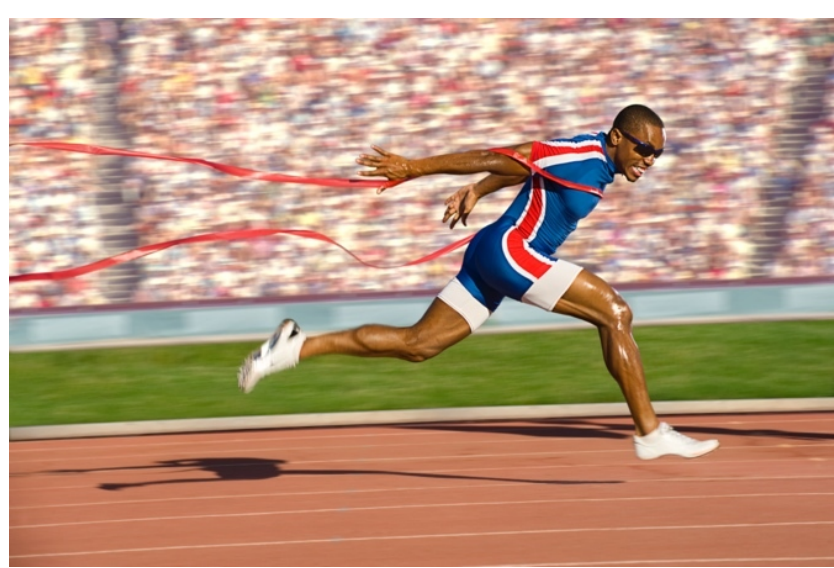

Figure 3. A runner, at the finish line

iStock photo

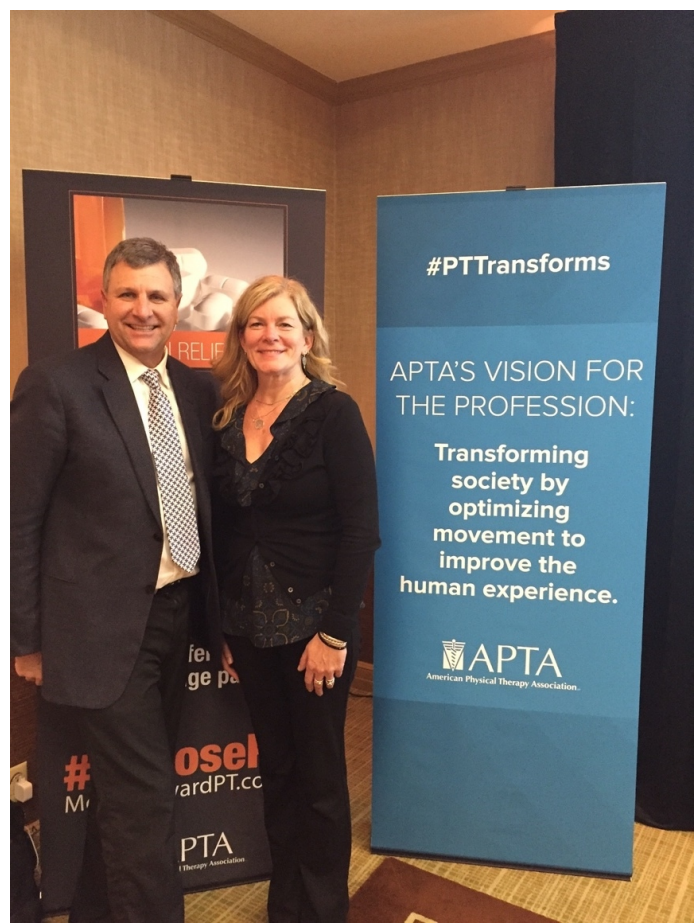

Figure 4. Movement System Summit attendees, Dr. Barb Hoogenboom and Dr. Mike Voight, editors of the International Journal of Sports Physical Therapy, in Alexandria, Virginia, in 2016

certainly hope that future endeavors include the development of some common movement system diagnoses for all areas of practice which could influence the standardization of practice. I (and my co-authors in a prior Point of View paper in $P T$ ) ) believe that the core documents which guide the profession should continue to evolve to adapt to movement system language, thinking, and expanded clinical reasoning related to movement. ${ }^{3}$ The Movement System Special Issue presented by IJSPT is a conscious attempt by the editorial staff to illuminate the movement system in the practice of sports physical therapy, and keep the discussion going. I am grateful to each of our contributors for their work regarding 
movement system concepts, illustration of the use of terminology, and conceptual linking within/among systems, all of which contribute to the evolution of the practice of physical therapy, especially sports physical therapy.
Submitted: December 01, 2021 CST, Accepted: December 17, 2021 CST 


\section{REFERENCES}

1. Merriam-Webster.com Dictionary, MerriamWebster. Published online 2021. https://www.merria m-webster.com/dictionary/poetry\%20in\%20motion

2. The American Physical Therapy Association. In: Diagnosis by Physical Therapists: HOD P06-2-10-09 Amended HOD P06-08-06-07; HOD P06-97-06-19; HOD 06-95-12-07; HOD 06-94-22-35; Initial HOD 06-84-19-78.
3. Sebelski CA, Hoogenboom BJ, Hayes AM, Held Bradford E, Wainwright SF, Huhn K. The Intersection of Movement and Clinical Reasoning: Embodying "Body as a Teacher" to Advance the Profession and Practice. Physical Therapy. 2020;100(2):201-204. doi:1 $\underline{0.1093 / \mathrm{ptj} / \mathrm{pzz} 137}$

4. Ness BM, Taylor AL, Haberl MD, Reuteman PF, Borgert AJ. Clinical observation and analysis of movement quality during performance of the start excursion balance test. Int J Sports Phys Ther. 2015;10(2):168-177. 